\title{
Análise preliminar de riscos (APR) aplicada as atividades desenvolvidas por trabalhadores do Complexo do Ver-O-Peso, Belém/PA
}

\author{
Preliminary hazard analysis (PHA) applied to activities developed by workers in the Ver-O-Peso \\ Complex, Belém/PA \\ Análisis preliminar de riesgos (APR) aplicado a las actividades desarrolladas por los trabajadores \\ del Complejo Ver-O-Peso, Belém/PA
}

Recebido: 25/01/2021 | Revisado: 26/01/2021 | Aceito: 31/01/2021 | Publicado: 07/02/2021

Cézar Di Paula Da Silva Pinheiro
ORCID: https://orcid.org/0000-0003-3946-2379
Instituto Tecnológico Vale, Brasil
E-mail: cezarpinheiroo18@ @mail.com
Leandro Marques Torres
ORCID: https://orcid.org/0000-0001-5976-6340
Universidade Federal Rural da Amazônia, Brasil
E-mail: leandrotorres15@ yahoo.com.br
Sarah Dias Azevedo
ORCID: https://orcid.org/0000-0002-5105-1794
Universidade Federal Rural da Amazônia, Brasil
E-mail: saaahaazevedo@ @mail.com
Amanda Gama Rosa
ORCID: https://orcid.org/0000-0002-9053-2777
Universidade Federal do Pará, Brasil
E-mail: amandagamarosa@ @mail.com

\begin{abstract}
Resumo
A quantidade de mercados e feiras livres no município de Belém/PA vem se multiplicando de forma considerável. Estas possuem uma dinâmica de formação e funcionamento bastante particular, apresentando, muita das vezes, péssimas condições de trabalho com pouca ou nenhuma higiene e segurança. O objetivo da pesquisa foi a identificação dos agentes de risco nas atividades desenvolvidas por trabalhadores do Complexo do Ver-o-Peso, Belém/PA, através da técnica de Análise Preliminar de Riscos. Foi realizada revisão bibliográfica e visitas in loco durante o mês de outubro de 2020. No total, foram identificados 27 potenciais perigos associados a diferentes atividades desenvolvidas pelos trabalhadores. Tais perigos estão relacionados aos agentes de riscos físicos, químicos, biológicos, ergonômicos e mecânicos ou de acidentes. A origem dos riscos encontrados advém de distintos elementos do processo de trabalho como: materiais, equipamentos, conforto acústico e térmico, instalações e iluminação. O risco biológico apresentou-se como maior potencial de risco para os trabalhadores locais. Os riscos físicos, químicos e a maior parte dos agentes ergonômicos e mecânicos ou de acidentes apresentam potencial de risco moderado. Revelouse a necessidade de investimentos do poder público, voltadas ao treinamento e capacitação dos profissionais, além de melhorias na estrutura física do complexo.
\end{abstract}

Palavras-chave: Segurança do trabalho; Saúde ocupacional; Gerenciamento de riscos; Risco ambiental; Feira livre.

\begin{abstract}
The number of markets and street markets in the municipality of Belém/PA has been multiplying in an enhanced manner. These have very particular training and functioning dynamics, often presenting terrible working conditions with few or no hygiene and safety. The objective of the research was to identify risk agents in the activities developed by workers at the Ver-o-Peso Complex, Belém/PA, using the Preliminary Hazard Analysis technique. Bibliographic review and site visits were carried out during October 2020. In total, 27 potential hazards associated with different activities developed by workers were identified. These hazards are related to physical, chemical, biological, ergonomic and mechanical risk agents or accidents. The origin of the risks found comes from different elements of the work process, such as: materials, equipment, acoustic and thermal comfort, installations and lighting. The biological risk was the greatest risk potential for local workers. Physical and chemical risks and most ergonomic and mechanical agents or accidents have moderate risk potential. It revealed the need for investments by the government, aimed at training and qualifying local workers, in addition to improvements in the physical structure of the complex.
\end{abstract}

Keywords: Occupational safety; Occupational health; Risk management; Environmental risk; Street market. 


\section{Resumen}

El número de mercados y mercados abiertos en la ciudad de Belém/PA se ha multiplicado considerablemente. Estos tienen una dinámica de formación y funcionamiento muy particular, presentando a menudo condiciones de trabajo pésimas con poca o ninguna higiene y seguridad. El objetivo de esta investigación fue identificar agentes de riesgo en las actividades desarrolladas por los trabajadores del Complejo Ver-o-Peso, Belém/PA, utilizando la técnica de Análisis Preliminar de Riesgos. Durante octubre de 2020 se realizó revisión bibliográfica y visitas in situ. En total, se identificaron 27 peligros potenciales asociados a las diferentes actividades desarrolladas por los trabajadores. Estos peligros están relacionados con agentes de riesgos físicos, químicos, biológicos, ergonómicos y mecánicos. El origen de los riesgos encontrados proviene de diferentes elementos del proceso de trabajo, tales como: materiales, equipamiento, confort acústico y térmico, instalaciones e iluminación. El riesgo biológico fue el mayor riesgo potencial para los trabajadores locales. Los riesgos físicos y químicos y la mayoría de los agentes ergonómicos y mecánicos tienen un potencial de riesgo moderado. Se reveló la necesidad de inversiones por parte de las Administraciones Públicas, orientadas a la formación y calificación de los profesionales, así como a mejoras en la estructura física del complejo.

Palabras clave: Seguridad ocupacional; Salud ocupacional; Gestión de riesgos; Riesgo ambiental; Mercado abierto.

\section{Introdução}

Mercados e feiras ao ar livre são importantes espaços para a comercialização de produtos, onde ocorrem um intenso fluxo de pessoas, bens e mercadorias. Tais lugares, apresentam diferentes dimensões socioespaciais, podendo ser realizadas tanto ao ar livre, como em vias públicas e demais espaços urbanos (Mascarenhas \& Dolzani, 2008; Azevedo \& Queiroz, 2013; Vedana, 2013; Pereira et al., 2017). A atividade dos feirantes é considerada como um trabalho, muita das vezes, precário, onde a dinâmica das atividades, aliada a falta de conhecimento sobre boas práticas de manipulação e comercialização comumente expõe os trabalhadores a condições inadequadas de saúde e segurança do trabalho relacionadas, sobretudo, a falta de higiene, segurança, organização e ausência de infraestrutura adequada, assim como outros fatores associados a demandas laborais excessivas e longa jornada de trabalho (Almeida \& Pena, 2011; Pereira, 2015; Jesus Carvalho \& Aguiar, 2017).

Entre as características das operações de compra e venda em feiras livres, destaca-se a rapidez na prestação dos serviços, que "[...] quando realizado em condições desfavoráveis, com utensílios e equipamentos inadequados, ruídos excessivos, calor e iluminação insuficiente causam desgaste humano, expondo o trabalhador a doenças ocupacionais" (Montelo et al., 2011, p. 263). Dessa forma, em um ambiente impróprio, o tempo de exposição, concentração/intensidade e demais características dos agentes ambientais encontram-se diretamente relacionados ao surgimento de doenças do trabalho, patologias e demais riscos associados a fatores ergonômicos ou de acidentes.

Nessa perspectiva, a segurança, a higiene e a saúde no ambiente de trabalho deve englobar todos os ramos de atividades, incluindo o trabalho informal ou ambulante, visando minimizar os acidentes de trabalho, doenças ocupacionais e a proteção da integridade e capacidade laboral através do monitoramento ou eliminação dos agentes e riscos ambientais através do cumprimento das devidas normas de segurança do trabalho (Silva et al., 2006; Montelo et al., 2011; Wachowicz, 2012; Carvalho et al., 2016).

Assim, torna-se necessária a criação de ferramentas de análise e prevenção de riscos, sendo imprescindível para o planejamento de qualquer atividade laboral (Saliba, 2019; Castro et al., 2019). Nesse sentido, a Análise Preliminar de Riscos (APR), também conhecida como Preliminary Hazard Analysis (PHA), vem sendo amplamente utilizada para o reconhecimento de potenciais riscos no ambiente de trabalho a partir da identificação de situações de perigo, eventos iniciadores em potencial e demais acontecimentos que possam causar acidentes no ambiente de trabalho (Amorim, 2010; Dogramadzi et al., 2014). Na APR são realizados levantamentos a respeito das inúmeras causas que podem promover a ocorrência de determinados eventos, assim como suas respectivas consequências para a segurança e saúde do trabalhador, sendo então realizada uma avaliação qualitativa da frequência de ocorrência dos cenários descritos, do grau de severidade e o nível de risco de cada cenário identificado na análise (Barros, 2013). 
Alguns estudos relacionados a APR vem sendo realizados no Brasil (Sousa \& Meideiros Jerônimo, 2014; Castro et al., 2019), adaptando a técnica de acordo com diferentes objetivos. Neves e Costa (2019) usaram a ferramenta como forma de analisar e mensurar os riscos ambientais e de segurança que visitantes de uma trilha ecológica estavam sujeitos. Enquanto que Viana et al. (2014) utilizaram como instrumento para a identificação dos principais riscos/perigos envolvidos na fase de acabamento e revestimento de um edifício. Em ambos os casos, a técnica mostrou-se eficaz e possibilitou a indicação de medidas mitigadoras e preventivas aos riscos que envolviam as respectivas pesquisas. A caracterização de riscos de acidentes relacionados a espaços públicos, como no caso de mercados e feiras ao ar livre, ainda é pouco conhecida. Assim, torna-se de grande importância a realização de maiores estudos que sejam capazes de agregar informações sobre possíveis riscos à saúde e segurança dos profissionais envolvidos em tais atividades, uma vez que os mesmos estão sujeitos a diferentes tipos de situações de perigo.

A quantidade de mercados e feiras livres no município de Belém/PA vem se multiplicando de forma considerável ao longo dos anos. Tais áreas possuem uma dinâmica de formação e funcionamento bastante particular apresentando, quase sempre, péssimas condições de trabalho, com pouca ou nenhuma higiene e segurança, e a comercialização dos produtos ao ar livre, sem as devidas instalações ou fiscalizações (Teixeira \& Coutinho, 2010; Oliveira Souza \& Pontes, 2020; Rosário et al., 2020). Dessa forma, o objetivo da pesquisa foi o de identificar os agentes de risco na execução das atividades desenvolvidas por trabalhadores do Complexo do Ver-o-Peso, Belém/PA, através da técnica de Análise Preliminar de Riscos. Apresentando como produto final uma listagem dos riscos encontrados no local.

\section{Material e Métodos}

\subsection{Caracterização da área de estudo}

Localizado na extensão da orla fluvial de Belém/PA, o Complexo do Ver-o-Peso é um importante espaço turístico de comercio e de interações sociais da capital paraense, possuindo o título de maior feira ao ar livre da América Latina, além de ser considerado uma das sete maravilhas do Brasil (Nascimento \& Rodrigues, 2011; Silva, 2011). O espaço é administrado pelas Secretarias Municipais de Meio Ambiente, Saúde, Urbanismo em conjunto com Secretaria Municipal de Economia (SECON), responsável pelo cadastro dos trabalhadores do mercado (Sousa et al., 2017). O Complexo é composto por 22 setores (Carvalho, 2011), que incluem as áreas de estudo desta pesquisa: duas feiras (Feira do Ver-o-Peso e Feira do Açaí), dois mercados (Mercado de Peixe e Mercado de Carne) e uma doca de embarcações (Doca do Ver-o-Peso) (Figura 1). 
Figura 1 - Localização do Complexo do Ver-o-Peso em Belém/PA.
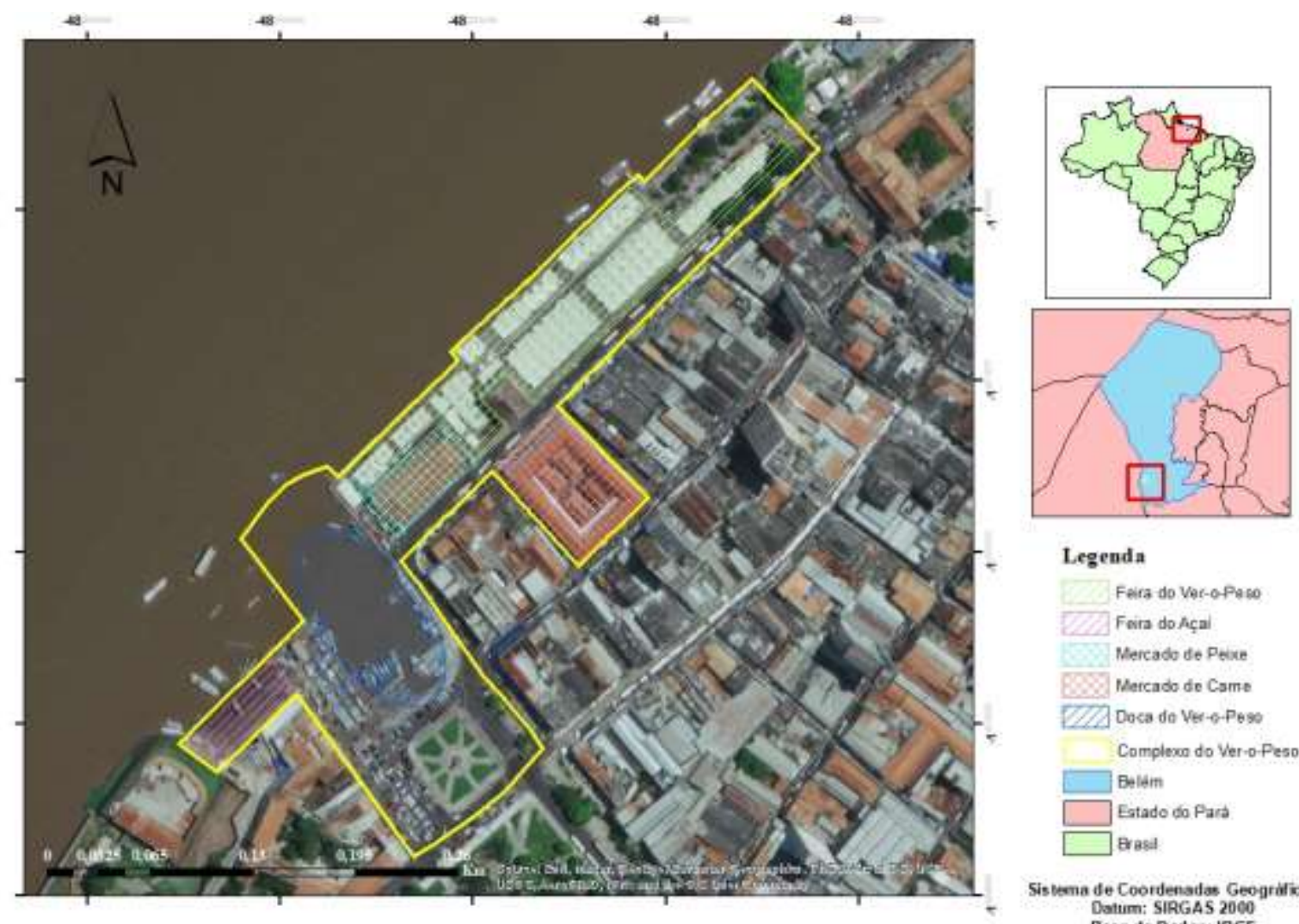

Q2.A Fwira do Açal

Mercado de Peoce

Q88. Mercado de Came

QZ2 Doca do Ves-o Poso

Complexo do Ver-o Peso

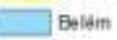

$\square$ Eatado do Pard

Sisvema de Coordenadas Geogräricas Datum: SIRGAS 2060 Cemer Pinheiro

Fonte: Autores (2020).

Em seu comércio, circulam os mais variados produtos como frutas, peixes, artesanatos, ervas e medicamentos naturais (Carvalho, 2011; Pombo Geertsma, 2019; Rodríguez et al., 2020). Os comerciantes locais começam a labuta desde cedo, com destaque para os vendedores de hortaliças, peixes e frutos do mar, tendo em vista que a demanda pelos consumidores destes produtos inicia horas antes do alvorecer (Sousa, 2017). A Associação dos Trabalhadores do Ver-o-Peso estima que existam em torno de 1.250 permissionários cadastrados (Taketa et al., 2018). Contudo, devido a dinâmica da feira que envolve revezamento de pessoal em um mesmo espaço, com inúmeras atividades em horários distintos, é possível que o total de trabalhadores do complexo chegue até 5 mil pessoas. Desde de sua formação até a atualidade, o Complexo do Ver-o-Peso passou por algumas intervenções com o intuito de ampliar o ambiente a atender as necessidades dos feirantes e consumidores (Secon, 2019) (Figura 2). 
Figura 2 - Principais modificações e reformas no Complexo do Ver-o-Peso entre os anos de 1688 a 2020.

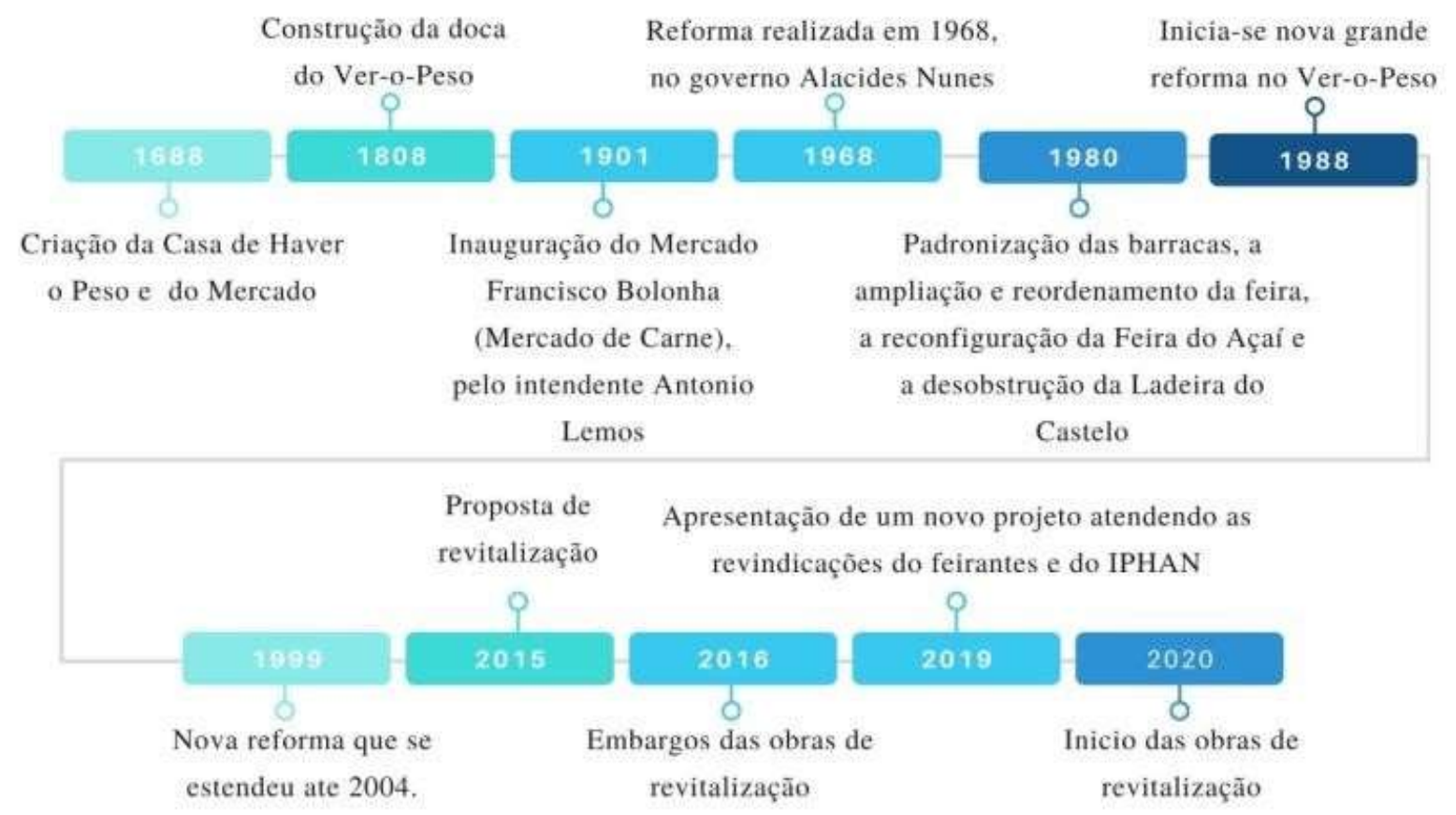

Fonte: Adaptado de Santos e Sepêda Filho (2016) e SECON (2019).

O longo período sem reformas, 2004 a 2020, deixou o Ver-o-Peso em situação precária, colocando a saúde dos feirantes e frequentadores em risco. Em levantamento realizado em 2015 pela empresa DPJ Arquitetura e Engenharia Ltda., foram identificados diversos problemas nas dependências do mercado. Alguns destes relacionados a precariedade dos equipamentos que, em vários casos, não estavam adequados para o uso, deixando de atender as recomendações da Vigilância Sanitária. Além disso, também foram observados outros aspectos relacionados ao péssimo estado de conservação da cobertura de lona tensionada, que foi considerada como ineficiente para a proteção contra a água da chuva e para o conforto térmico esperado aos feirantes e frequentadores. Esta apresentava danos estruturais provocados principalmente por infiltrações. Outro ponto estava relacionado ao sistema elétrico que, em geral, encontrava-se em péssimas condições de conservação (Dpj, 2015).

\subsection{Procedimentos metodológicos}

A metodologia é tipo qualitativa (Pereira et al., 2018), a qual permitiu, entre outras coisas, uma avaliação detalhada do risco relacionado a cada um dos cenários identificados no ambiente de estudo.

Inicialmente foi realizada uma vasta revisão bibliográfica, a partir da leitura de artigos, livros e demais trabalhos de cunho científico como forma de fundamentar teoricamente a pesquisa, onde foram pesquisados estudos de caso que tratavam a respeito da aplicabilidade da APR a partir de diferentes objetivos. Secundariamente, optou-se pela procura de artigos que abordavam sobre diferentes aspectos do Ver-o-Peso, como forma de conhecer o histórico de ocupação da área e suas principais problemáticas. Nesta etapa, também foi realizada consultas ao site da prefeitura de Belém e demais secretarias responsáveis pela gestão do local, assim como verificação do mapa geral de setores do Complexo (Carvalho, 2011).

Posteriormente, foram realizadas visitas in loco durante o mês de outubro de 2020, onde ocorreram análises descritivas e fotográficas acerca dos potenciais riscos aos quais os trabalhadores do local estão sujeitos, levando-se em consideração cinco tipos de riscos: (i) físicos, (ii) químicos, (iii) biológicos, (iv) ergonômicos e (v) mecânicos ou de acidentes (Quadro 1). 
Quadro 1 - Classificação dos riscos no ambiente laboral.

\begin{tabular}{|c|c|}
\hline RISCOS & DESCRIÇÃO \\
\hline Físicos & $\begin{array}{l}\text { Consideram-se agentes de risco físico as diversas formas de energia a que possam estar } \\
\text { expostos os trabalhadores (ruído, calor, frio, pressão, umidade, radiações ionizantes e } \\
\text { não ionizantes, vibração etc.). }\end{array}$ \\
\hline Químicos & $\begin{array}{l}\text { Consideram-se agentes de risco químico as substâncias, os compostos ou produtos que } \\
\text { possam penetrar no organismo do trabalhador pela via respiratória ou que, pela } \\
\text { natureza da atividade de exposição, possam ter contato ou serem absorvidos pelo } \\
\text { organismo através da pele ou por ingestão (poeiras, fumos, gases, vapores, névoas, } \\
\text { neblinas e substancias compostas ou produtos químicos em geral). }\end{array}$ \\
\hline Biológicos & $\begin{array}{l}\text { Consideram-se como agentes de risco biológico as bactérias, os vírus, fungos, parasitas, } \\
\text { entre outros. }\end{array}$ \\
\hline Ergonômicos & $\begin{array}{l}\text { Qualquer fator que possa interferir nas características psicofisiológicas do trabalhador, } \\
\text { causando desconforto ou afetando a sua saúde (levantamento de peso, ritmo excessivo } \\
\text { de trabalho, monotonia, repetitividade, postura inadequada de trabalho, jornadas longas } \\
\text { de trabalho, trabalho em turno e noturno, iluminação inadequada etc.). }\end{array}$ \\
\hline Mecânicos ou de acidentes & $\begin{array}{l}\text { Qualquer fator que coloque o trabalhador em situação vulnerável, afetando a sua } \\
\text { integridade e/ou seu bem-estar físico e psíquico (probabilidade de incêndio e explosão, } \\
\text { eletricidade, máquinas e equipamentos sem proteção, armazenamento inadequado, } \\
\text { quedas e animais peçonhentos etc.). }\end{array}$ \\
\hline
\end{tabular}

Fonte: Adaptado de NR 9 (2019) e Silva (2018).

A APR foi realizada a partir de uma adaptação das metodologias propostas por Amorim (2010) e Aguiar (2011). As análises compreenderam a execução das seguintes etapas: (i) definição do objetivo e da finalidade da análise; (ii) visitas em campo para análise dos perigos (as anotações foram registradas no diário de campo); (iii) organização e tabulação das anotações com o auxílio do software IBM SPSS (v.26); (iv) realização da APR a partir de preenchimento do formulário (Quadro 2); (v) elaboração das estatísticas de acordo com os cenários identificados por categoria de risco (frequência e severidade); e (vi) análise dos resultados com posteriores recomendações

Quadro 2 - Modelo de formulário para a análise preliminar de riscos.

\begin{tabular}{|c|c|c|c|c|c|c|}
\hline \multicolumn{7}{|c|}{ ANÁLISE PRELIMINAR DE RISCOS (APR) } \\
\hline \multirow{2}{*}{ Perigo } & \multirow{2}{*}{ Causa (s) } & \multirow{2}{*}{ Efeito (s) } & \multicolumn{3}{|c|}{ Categorias } & \multirow{2}{*}{$\begin{array}{c}\text { Medidas } \\
\text { Preventivas ou } \\
\text { Corretivas }\end{array}$} \\
\hline & & & Frequência & Severidade & Risco & \\
\hline
\end{tabular}

Fonte: Adaptado de Amorim (2010) e Aguiar (2011).

As colunas são preenchidas conforme as descrições a seguir (Amorim, 2010; Aguiar, 2011):

- Perigo: Identificação dos perigos (eventos com potencial de causar danos);

- Causa (s): Causa (s) de cada perigo identificado; 
- $\quad$ Efeito (s): Efeito (s) negativo (s) de cada perigo identificado;

- Categorias de Frequência (F): Indicação qualitativa da frequência esperada de ocorrência para cada cenário identificado (Quadro 3);

Quadro 3 - Categorias de frequência dos cenários da análise preliminar de riscos.

\begin{tabular}{|c|c|l|}
\hline CATEGORIA & DENOMINAÇÃO & \multicolumn{1}{|c|}{ DESCRIÇÃO } \\
\hline A & Extremamente remota & $\begin{array}{l}\text { Conceitualmente possível, mas extremamente } \\
\text { improvável. }\end{array}$ \\
\hline B & Remota & $\begin{array}{l}\text { Não esperado ocorrer, apesar de haver referências } \\
\text { históricas. }\end{array}$ \\
\hline C & Pouco provável & Possível ocorrer mais de uma vez. \\
\hline D & Provável & Esperado ocorrer mais de uma vez. \\
\hline E & Frequente & Esperado ocorrer muitas vezes. \\
\hline
\end{tabular}

Fonte: Adaptado de Amorim (2010) e Aguiar (2011).

- Categorias de Severidade (S): Indicação qualitativa do grau de severidade das consequências de cada um dos cenários identificados (Quadro 4);

Quadro 4 - Categorias de severidade dos cenários da análise preliminar de riscos.

\begin{tabular}{|c|c|c|}
\hline Categoria & Denominação & Descrição \\
\hline I & Desprezível & $\begin{array}{l}\text { Sem danos ou danos insignificantes aos equipamentos, à } \\
\text { propriedade e/ou ao meio ambiente; não ocorrem } \\
\text { lesões/mortes de pessoas, o máximo que pode ocorrer são } \\
\text { casos de primeiros socorros ou tratamento médico menor. }\end{array}$ \\
\hline II & Marginal & $\begin{array}{l}\text { Danos leves aos equipamentos, à propriedade e/ou ao meio } \\
\text { ambiente (os danos materiais são controláveis e/ou de baixo } \\
\text { custo); Lesões leves em prestadores de serviço ou de } \\
\text { membros da comunidade. }\end{array}$ \\
\hline III & Crítica & $\begin{array}{l}\text { Danos severos aos equipamentos, à propriedade e/ou ao } \\
\text { meio ambiente; Lesões de gravidade moderada em } \\
\text { prestadores de serviço ou em membros da sociedade } \\
\text { (probabilidade remota de morte); Exige ações corretivas } \\
\text { imediatas para evitar seu desdobramento em catástrofe. }\end{array}$ \\
\hline IV & Catastrófica & $\begin{array}{l}\text { Danos irreparáveis aos equipamentos, à a propriedade e/ou } \\
\text { ao meio ambiente (reparação lenta ou impossível); provoca } \\
\text { mortes ou lesões graves em várias pessoas. }\end{array}$ \\
\hline
\end{tabular}

Fonte: Adaptado de Amorim (2010) e Aguiar (2011). 
- Categoria de Risco (R): Combinação das categorias de frequência com as de severidade, a qual fornece uma indicação qualitativa do nível de risco de cada cenário identificado na análise, permitindo visualizar os cenários de acidente de maior impacto (Quadro 5).

Quadro 5 - Matriz de classificação do grau de risco usado na análise preliminar de riscos.

\begin{tabular}{|c|c|c|c|c|c|c|}
\hline \multicolumn{6}{|c|}{ FREQUÊNCIA } & \\
\hline A & B & $\mathrm{C}$ & D & $\mathbf{E}$ & & \multirow{5}{*}{$\underset{\mathbb{Z}}{2}$} \\
\hline 2 & 3 & 4 & 5 & 5 & IV & \\
\hline 1 & 2 & 3 & 4 & 5 & III & \\
\hline 1 & 1 & 2 & 3 & 4 & II & \\
\hline 1 & 1 & 1 & 2 & 3 & I & \\
\hline
\end{tabular}

1 = desprezível; 2 = menor; 3 = moderado; 4 = sério; 5 = crítico. Fonte: Adaptado de Amorim (2010).

- Medidas Preventivas ou Corretivas: Medidas que devem ser tomadas para diminuir a frequência ou severidade do acidente ou quaisquer observações pertinentes ao cenário de acidente em estudo.

As colunas "Efeito (s)" e "Medidas preventivas ou corretivas" foram preenchidas a partir de uma revisão sistemática da literatura. Assim como uma adaptação dos preceitos estabelecidos pelas Normas Regulamentadoras (NRs) relativas à segurança e medicina do trabalho. Especificamente, NR 9 (programa de prevenção de riscos ambientais), NR 15 (atividades e operações insalubres) e NR 17 (ergonomia). Além da Norma de Higiene Ocupacional - NHO 6 (avaliação da exposição ocupacional ao calor).

\section{Resultados e Discussão}

Foram identificados 27 potenciais perigos associados a diferentes atividades desenvolvidas pelos trabalhadores do Complexo do Ver-o-Peso comuns, em sua grande maioria, as diferentes partes constituintes do local (Feira do Ver-o-Peso, Mercado de Peixe e Mercado de Carne, principalmente). Tais perigos, estão relacionados aos agentes de riscos físicos, químicos, biológicos, ergonômicos e mecânicos ou de acidentes. Os resultados da APR podem ser visualizados a seguir (Quadro 6). 
Research, Society and Development, v. 10, n. 2, e12210212332, 2021

(CC BY 4.0) | ISSN 2525-3409 | DOI: http://dx.doi.org/10.33448/rsd-v10i2.12332

Quadro 6 - Resultados da análise preliminar de riscos.

\begin{tabular}{|c|c|c|c|c|c|c|c|}
\hline & \multicolumn{7}{|c|}{ Análise Preliminar De Riscos (APR) } \\
\hline & \multirow{2}{*}{ Perigo } & \multirow{2}{*}{ Causa (s) } & \multirow{2}{*}{ Efeito (s) } & \multicolumn{3}{|c|}{ Categorias } & \multirow{2}{*}{$\begin{array}{l}\text { Medidas preventivas ou } \\
\text { corretivas }\end{array}$} \\
\hline & & & & $\mathbf{F}$ & $\mathbf{S}$ & $\mathbf{R}$ & \\
\hline \multirow{3}{*}{ 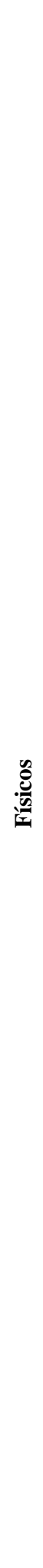 } & Calor & $\begin{array}{l}\text { Ambiente laboral mal } \\
\text { projetado; Calor gerado por } \\
\text { equipamentos/ objetos } \\
\text { (fogões, fornos, panelas } \\
\text { industriais e outros); } \\
\text { Péssimo estado de } \\
\text { conservação da cobertura de } \\
\text { lona tensionada; Ambiente } \\
\text { laboral mal projetado; Calor } \\
\text { do próprio ambiente. }\end{array}$ & $\begin{array}{l}\text { Desidratação; Fadiga; } \\
\text { Desconforto térmico; } \\
\text { Mal-estar; Dor de } \\
\text { cabeça; Insolação; } \\
\text { Doenças de pele; } \\
\text { Baixa produtividade. }\end{array}$ & $\mathrm{E}$ & I & 3 & $\begin{array}{l}\text { Disponibilização de água e } \\
\text { sais minerais; Protetor solar; } \\
\text { Educação e treinamento de } \\
\text { trabalhadores } \\
\text { aclimatização, hidratação, } \\
\text { pausas, sinais e sintomas da } \\
\text { exposição ao calor, condutas } \\
\text { de Introdução de pausas; Uso } \\
\text { de barreiras refletoras ou } \\
\text { absorventes; Sistemas de } \\
\text { ventilação adequados; } \\
\text { Fornecimento de vestimentas } \\
\text { de trabalho adequadas e em } \\
\text { condições de conforto; } \\
\text { Avaliação da exposição dos } \\
\text { trabalhadores; Controle } \\
\text { médico. }\end{array}$ \\
\hline & Ruído & $\begin{array}{l}\text { Intenso fluxo de pessoas; } \\
\text { Dialogo entre feirantes e } \\
\text { clientes; } \\
\text { funcionamento } \\
\text { equipamentos; Intenso fluxo } \\
\text { de veículos. }\end{array}$ & $\begin{array}{l}\text { Perda de audição; } \\
\text { Estresse; Surdez; } \\
\text { Alterações do sistema } \\
\text { imunológico; } \\
\text { Dificuldade de } \\
\text { comunicação; Doenças } \\
\text { cardiovasculares. }\end{array}$ & $\mathrm{E}$ & I & 3 & $\begin{array}{l}\text { Educação e conscientização } \\
\text { de trabalhadores e usuários; } \\
\text { Substituição } \\
\text { equipamentos por outros } \\
\text { menos ruidosos; Reduzir } \\
\text { impactos, quando possível; } \\
\text { Manutenção preventiva dos } \\
\text { equipamentos; Mínimo de } \\
\text { equipamentos ligados } \\
\text { simultaneamente; } \\
\text { Monitoramento do ruído; } \\
\text { Barreiras sonoras; Rodízio de } \\
\text { trabalhadores; Planejamento } \\
\text { urbano; Fornecimento de } \\
\text { EPI. }\end{array}$ \\
\hline & Umidade & $\begin{array}{lrr}\text { Ambiente } & \text { laboral } & \text { mal } \\
\text { projetado; Falta } & \text { de } \\
\text { manutenção; Umidade } & \text { do } \\
\text { próprio ambiente; Piso } \\
\text { molhado. }\end{array}$ & $\begin{array}{l}\text { Infiltração; Problemas } \\
\text { respiratórios } \\
\text { pulmonares; Doenças } \\
\text { de pele. Doenças } \\
\text { cardiovasculares. }\end{array}$ & $\mathrm{E}$ & I & 3 & $\begin{array}{l}\text { Melhoria da infraestrutura } \\
\text { local; } \\
\text { Manutenção periódica; } \\
\text { Fornecimento de EPI. }\end{array}$ \\
\hline
\end{tabular}


Research, Society and Development, v. 10, n. 2, e12210212332, 2021

(CC BY 4.0) | ISSN 2525-3409 | DOI: http://dx.doi.org/10.33448/rsd-v10i2.12332

\begin{tabular}{|c|c|c|c|c|c|c|c|}
\hline & Radiação solar & $\begin{array}{l}\text { Péssimo estado de } \\
\text { conservação da cobertura de } \\
\text { lona } \\
\text { Inexistência de abrigos; } \\
\text { Ambiente laboral mal } \\
\text { projetado. }\end{array}$ & $\begin{array}{l}\text { Insolação; } \\
\text { Desidratação; } \\
\text { Doenças de pele; } \\
\text { Diminuição } \\
\text { produtividade }\end{array}$ & $\mathrm{E}$ & I & 3 & $\begin{array}{l}\text { Disponibilização de água e } \\
\text { sais minerais; Protetor solar; } \\
\text { Uso de barreiras refletoras ou } \\
\text { absorventes; Sistemas de } \\
\text { ventilação adequados; } \\
\text { Fornecimento de vestimentas } \\
\text { de trabalho adequadas e em } \\
\text { condições de conforto. }\end{array}$ \\
\hline \multirow{3}{*}{ : } & Poeiras & $\begin{array}{l}\text { Poeira de varrição; Fezes de } \\
\text { animais. }\end{array}$ & $\begin{array}{l}\text { Alergias, desconforto, } \\
\text { perda momentânea da } \\
\text { visão; Doenças } \\
\text { respiratórias; } \\
\text { Problemas respiratórios } \\
\text { e pulmonares. }\end{array}$ & $\mathrm{E}$ & I & 3 & $\begin{array}{l}\text { Umidificação; } \\
\text { Fiscalização periódica; } \\
\text { Fornecimento de EPI }\end{array}$ \\
\hline & $\begin{array}{c}\text { Gases } \\
\text { ou vapores }\end{array}$ & $\begin{array}{l}\text { Fervura das panelas; } \\
\text { Vazamento de gás; Gases } \\
\text { provenientes } \\
\text { decompisção de resíduos } \\
\text { sólidos mal condicionados }\end{array}$ & $\begin{array}{l}\text { Doenças respiratórias; } \\
\text { Mal odores. }\end{array}$ & $\mathrm{E}$ & I & 3 & $\begin{array}{l}\text { Fiscalização periódica; } \\
\text { Melhoria da infraestrutura } \\
\text { local; Educação e } \\
\text { conscientização de } \\
\text { trabalhadores Melhoria no } \\
\text { gerenciamento dos resíduos } \\
\text { sólidos; Educação e } \\
\text { conscientização } \\
\text { trabalhadores; Fornecimento } \\
\text { de EPI. }\end{array}$ \\
\hline & Produtos químicos & $\begin{array}{l}\text { Produtos de limpeza; } \\
\text { Consumo de alimentos; } \\
\text { Manuseio de frutas, } \\
\text { verduras e outros produtos } \\
\text { com agrotóxicos; Falta de } \\
\text { equipamento de proteção } \\
\text { individual - EPI; Uso } \\
\text { inadequado de EPI. }\end{array}$ & $\begin{array}{l}\text { Doenças de pele; } \\
\text { Tonturas; Cólicas } \\
\text { abdominais; Náuseas; } \\
\text { Vômitos; Dificuldades } \\
\text { respiratórias; } \\
\text { Tremores; Irritações na } \\
\text { pele, nariz, garganta e } \\
\text { olhos. }\end{array}$ & $\mathrm{D}$ & II & 3 & $\begin{array}{l}\text { Educação e } \\
\text { de }\end{array}$ \\
\hline
\end{tabular}


Research, Society and Development, v. 10, n. 2, e12210212332, 2021

(CC BY 4.0) | ISSN 2525-3409 | DOI: http://dx.doi.org/10.33448/rsd-v10i2.12332

\begin{tabular}{|c|c|c|c|c|c|c|c|}
\hline 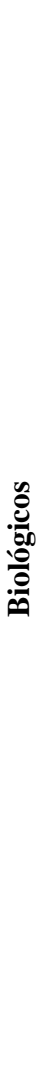 & Micro-organismos & $\begin{array}{l}\text { Preparo, venda e consumo } \\
\text { de alimentos; Falta de } \\
\text { higiene; Contato com } \\
\text { agentes } \\
\text { provenientes } \\
\text { decomposição de restos de } \\
\text { alimentos; } \quad \text { Disposição } \\
\text { inadequada de resíduos } \\
\text { sólidos; } \\
\text { inadequada da estocagem; } \\
\text { Manuseio de dinheiro; } \\
\text { Umidade; Contato com } \\
\text { animais; } \quad \text { Falta de } \\
\text { saneamento básico; Falta de } \\
\text { EPI; Uso inadequado de } \\
\text { EPI. }\end{array}$ & $\begin{array}{l}\text { Alergias; Doenças de } \\
\text { pele; Doenças } \\
\text { respiratórias; Doenças } \\
\text { infecciosas; } \\
\text { Desenvolvimento e } \\
\text { aparecimento de } \\
\text { vetores de doenças; } \\
\text { Mal odores. }\end{array}$ & $\mathrm{E}$ & III & 5 & $\begin{array}{l}\text { Eliminação ou redução do } \\
\text { contato do trabalhador com } \\
\text { as fontes potenciais; } \\
\text { Realização de procedimentos } \\
\text { de higienização } \\
\text { desinfecção do ambiente, } \\
\text { materiais e equipamentos } \\
\text { envolvidos; Educação e } \\
\text { treinamento de trabalhadores } \\
\text { (medidas de controle, normas } \\
\text { e procedimentos de higiene); } \\
\text { Melhoria no gerenciamento } \\
\text { dos resíduos sólidos; } \\
\text { Fornecimento de vestimentas } \\
\text { de trabalho adequadas e em } \\
\text { condições de conforto; } \\
\text { Existência de lavatório } \\
\text { exclusivo para higienização } \\
\text { das mãos; Controle médico; } \\
\text { Fornecimento de EPI. }\end{array}$ \\
\hline 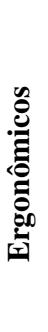 & Postura inadequada & $\begin{array}{l}\text { Uso de equipamentos } \\
\text { /objetos; Ambiente de } \\
\text { trabalho inadequado. }\end{array}$ & $\begin{array}{l}\text { Dores/Lesões na } \\
\text { coluna cervical e } \\
\text { vertebral; Dores } \\
\text { musculares; Estresse; } \\
\text { Fadigas; } \quad \text { Baixa } \\
\text { produtividade. }\end{array}$ & $\mathrm{D}$ & II & 3 & $\begin{array}{l}\text { Ginástica laboral; Educação } \\
\text { e treinamento de } \\
\text { trabalhadores. }\end{array}$ \\
\hline
\end{tabular}


Research, Society and Development, v. 10, n. 2, e12210212332, 2021

(CC BY 4.0) | ISSN 2525-3409 | DOI: http://dx.doi.org/10.33448/rsd-v10i2.12332

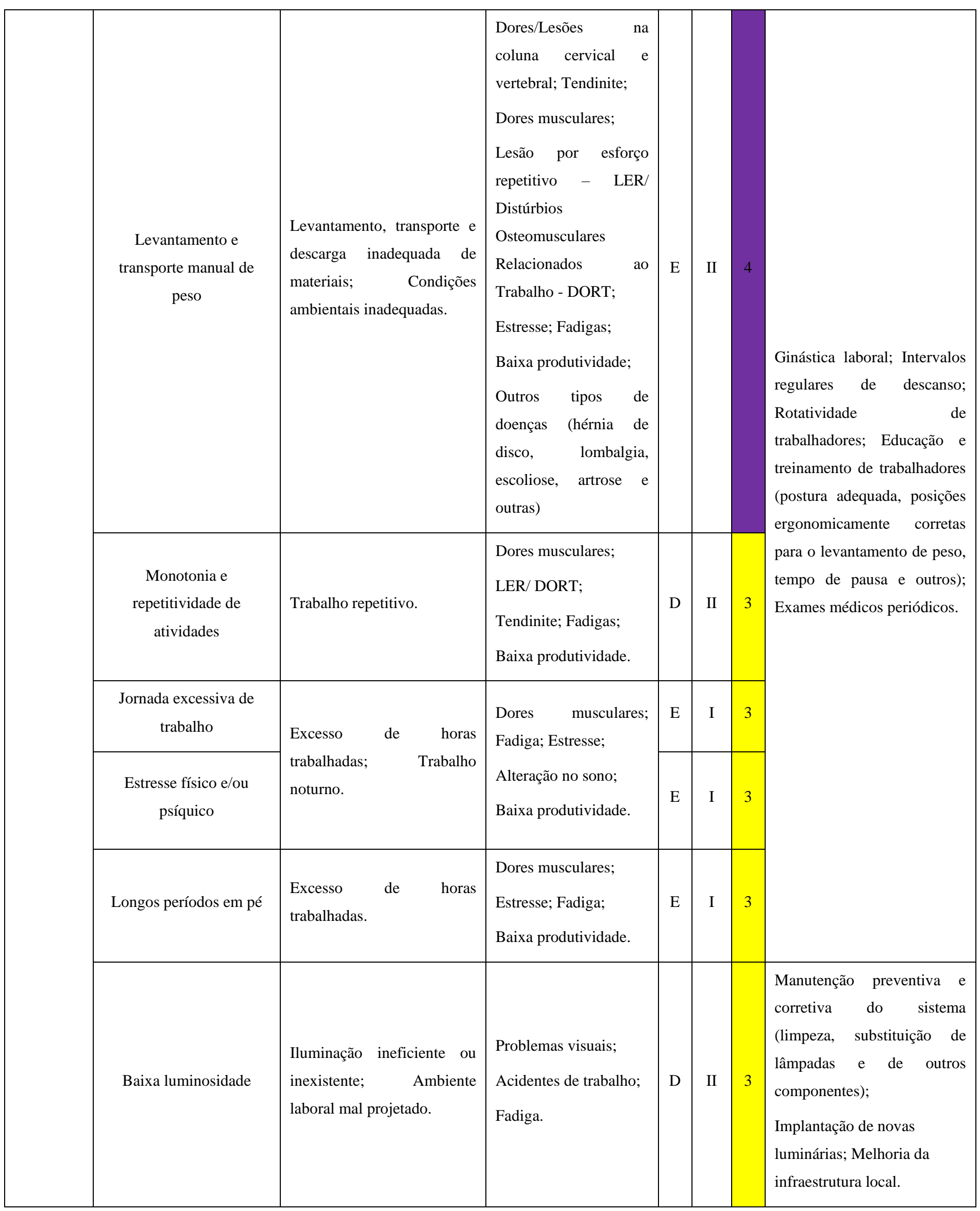




\begin{tabular}{|c|c|c|c|c|c|c|}
\hline Incêndio ou explosão & $\begin{array}{l}\text { Falta de atenção; } \\
\text { Desorganização; Falta de } \\
\text { manutenção; Vazamento de } \\
\text { produto inflamável; Fiações } \\
\text { elétricas e tomadas sem } \\
\text { proteção; Ambiente laboral } \\
\text { mal projetado. }\end{array}$ & $\begin{array}{l}\text { Incêndios; Explosões; } \\
\text { Lesões; Queimaduras; } \\
\text { Danos materiais; } \\
\text { Morte. }\end{array}$ & B & IV & 3 & $\begin{array}{l}\text { Manutenção e troca reguçar } \\
\text { de equipamentos e objetos } \\
\text { (válvulas, mangueiras, } \\
\text { registro e outros); Educação } \\
\text { e treinamento de } \\
\text { trabalhadores; Sistema de } \\
\text { combate a incêndio; } \\
\text { Melhoria da infraestrutura } \\
\text { local. }\end{array}$ \\
\hline Queimaduras & $\begin{array}{l}\text { Objetos aquecidos; Preparo } \\
\text { de comidas; Falta de } \\
\text { atenção; Desorganização; } \\
\text { Manuseio incorreto de } \\
\text { ferramentas/objetos; Falta } \\
\text { de treinamento; Situações de } \\
\text { estresse; Falta de EPI; Uso } \\
\text { inadequado de EPI. }\end{array}$ & $\begin{array}{l}\text { Lesões; Queimaduras; } \\
\text { Morte. }\end{array}$ & D & III & 4 & $\begin{array}{l}\text { Manutenção e troca reguçar } \\
\text { de equipamentos e objetos; } \\
\text { Educação e treinamento de } \\
\text { trabalhadores; Melhoria da } \\
\text { infraestrutura local; } \\
\text { Fornecimento de EPI. }\end{array}$ \\
\hline Choque elétrico & $\begin{array}{l}\text { Falta de manutenção; } \\
\text { Fiações elétricas e tomadas } \\
\text { sem proteção; Curto } \\
\text { circuito; Fios } \\
\text { Falta desgastados; } \\
\text { Desorganização; Ambiente } \\
\text { laboral mal projetado; Falta } \\
\text { de EPI; Uso inadequado de } \\
\text { EPI. }\end{array}$ & $\begin{array}{l}\text { Queimaduras; } \\
\text { Fraturas; Perdas de } \\
\text { membros; Danos } \\
\text { materiais; Morte. }\end{array}$ & $\mathrm{C}$ & III & 3 & $\begin{array}{l}\text { Manutenção preventiva dos } \\
\text { equipamentos; Substituição } \\
\text { das tomadas e da fiação } \\
\text { elétrica; Educação e } \\
\text { treinamento } \\
\text { trabalhadores; Melhoria da } \\
\text { infraestrutura local. }\end{array}$ \\
\hline Tropeços e quedas & $\begin{array}{l}\text { Quedas ou tropeços ao subir } \\
\text { ou descer escadarias; } \\
\text { Falta de atenção; } \\
\text { Desorganização; Resíduos } \\
\text { sólidos dispostos de forma } \\
\text { imprópria; Desnível do } \\
\text { chão; Falta de estruturas de } \\
\text { proteção; Piso molhado; } \\
\text { Calçadas ocupadas por } \\
\text { ambulantes/mercadorias; } \\
\text { Ambiente laboral mal } \\
\text { projetado. }\end{array}$ & $\begin{array}{l}\text { Quedas; Hematomas; } \\
\text { Escoriações; } \\
\text { Arranhões; Luxações; } \\
\text { Fraturas. }\end{array}$ & D & II & 3 & $\begin{array}{llr}\text { Degraus de superfície } \\
\text { aderente e corrimão guia; } \\
\text { Melhoria da infraestrutura } \\
\text { local; Melhoria } \\
\text { gerenciamento dos resíduos } \\
\text { sólidos. }\end{array}$ \\
\hline
\end{tabular}




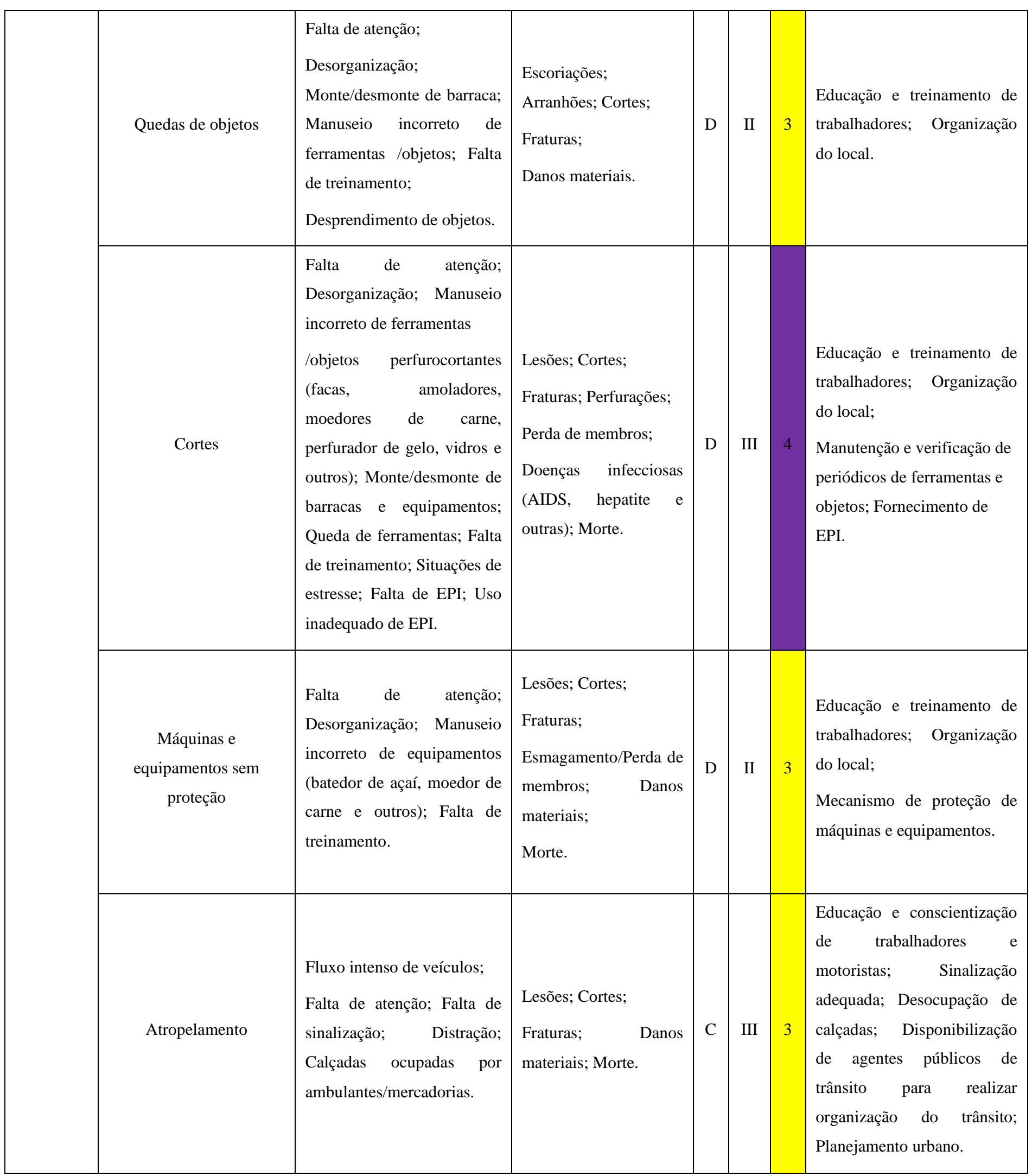




\begin{tabular}{|c|c|c|c|c|c|c|}
\hline $\begin{array}{l}\text { Colisão entre } \\
\text { embarcações* }\end{array}$ & $\begin{array}{l}\text { Falta de atenção; Fatores } \\
\text { ambientais (maré alta, } \\
\text { ventos e chuvas fortes); } \\
\text { Falha mecânica; Falta de } \\
\text { treinamento. }\end{array}$ & $\begin{array}{l}\text { Incêndios; Explosões; } \\
\text { Lesões; Queimaduras; } \\
\text { Danos materiais; } \\
\text { Danos ambientais; } \\
\text { Morte. }\end{array}$ & B & III & 2 & $\begin{array}{l}\text { Educação e treinamento de } \\
\text { trabalhadores; Organização } \\
\text { do local; Melhoria da } \\
\text { infraestrutura local; Plano de } \\
\text { contingência/emergência. }\end{array}$ \\
\hline $\begin{array}{l}\text { Vazamento de } \\
\text { combustíveis* }\end{array}$ & $\begin{array}{l}\text { Falta de atenção; Falha } \\
\text { mecânica; Falta de } \\
\text { treinamento; } \quad \text { Fatores } \\
\text { ambientais (maré alta, } \\
\text { ventos e chuvas fortes). }\end{array}$ & $\begin{array}{lr}\text { Incêndios; Explosões; } \\
\text { Exposição } \\
\text { contaminantes; } \\
\text { materiais; } \\
\text { ambientais. }\end{array}$ & $\mathrm{C}$ & III & 3 & $\begin{array}{l}\text { Educação e treinamento de } \\
\text { trabalhadores; Sistema de } \\
\text { combate a incêndio. }\end{array}$ \\
\hline
\end{tabular}

*Perigo observado exclusivamente para a Doca do Ver-o-Peso. Fonte: Autores (2020).

Parte dos perigos encontrados nesta análise estão de acordo com os observados por Montelo et al. (2011) e Pereira (2015) em suas respectivas pesquisas envolvendo riscos relacionados ao trabalho em feiras livres. A figura a seguir é uma síntese dos resultados obtidos a partir da APR (Figura 3).

Figura 3 - Número de ocorrências de situações de perigo de acordo com a classificação do grau de risco.

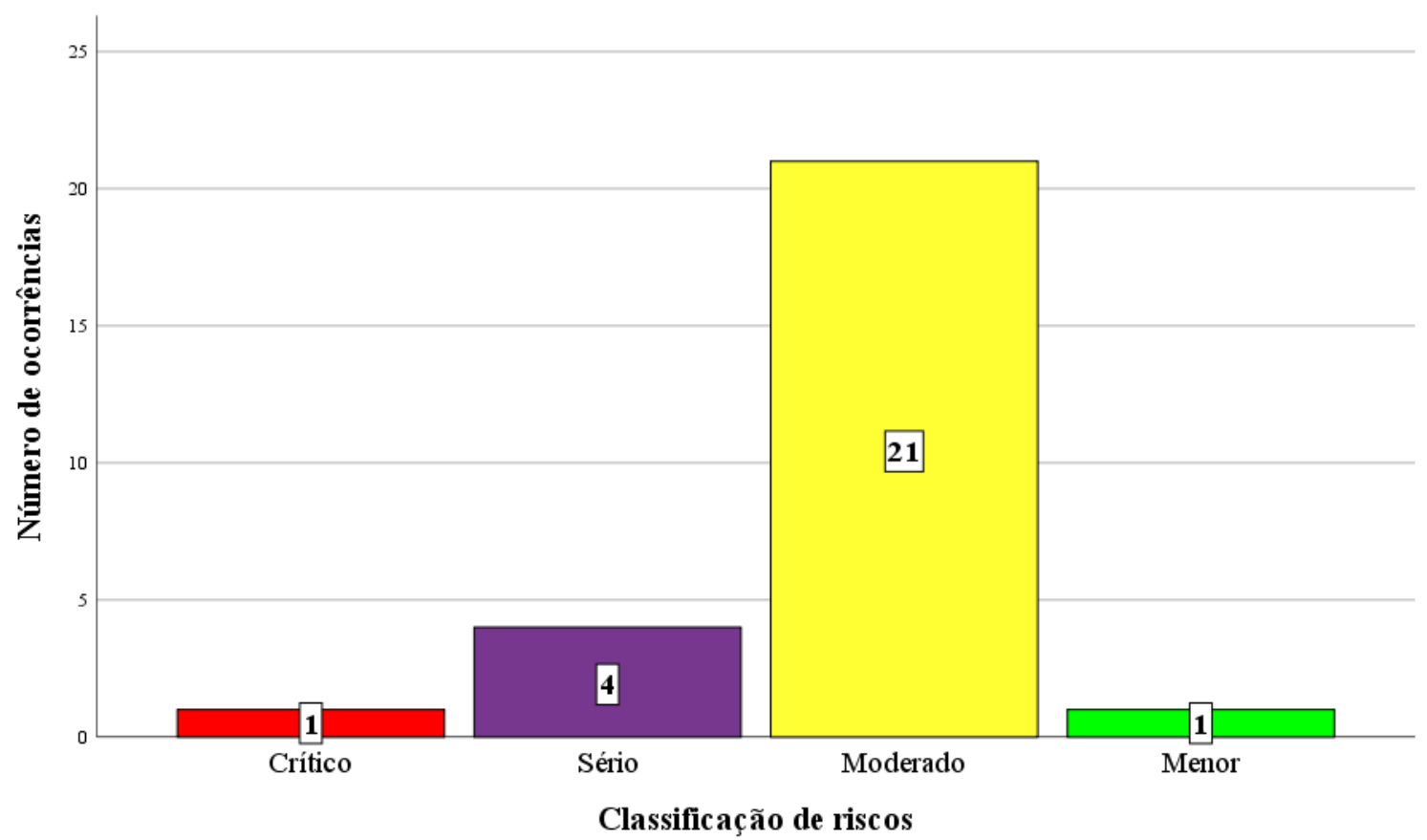

Fonte: Autores (2020).

Levando-se em consideração a classificação do grau de risco proposto nesta pesquisa, os resultados apontam que o maior potencial de risco para os trabalhadores locais, classificação 5 (crítico), está relacionado as atividades que envolvem os 
agentes biológicos associados a presença de micro-organismos. As causas estão ligadas as atividades que envolvem o preparo, venda e consumo de alimentos (Almondes Teixeira et al. 2015), onde os trabalhadores possuem contato direto com carnes, glândulas, vísceras, sangue, ossos e outras partes de animais que são vendidos no local. Outros aspectos estão associados a falta de higiene e a grande quantidade de resíduos sólidos que se encontram dispostos de modo impróprio em diversos pontos do Complexo. Além do manuseio de dinheiro, presença de animais e a falta ou uso incorreto de EPI.

Pesquisas sobre os aspectos higiênico-sanitários em feiras livres de diferentes regiões do País apontam as condições inadequadas de infraestrutura e falta de higiene nestes espaços (Minnaert \& Freitas, 2010; França et al., 2013; Martins \& Ferreira, 2018; Ferreira et al., 2020). Tais fatores, aliados ao precário conhecimento dos trabalhadores sobre boas práticas de manipulação e comercialização de produtos, contribuem para a presença de riscos biológicos através da contaminação e proliferação de doenças infecciosas e parasitárias relacionadas ao consumo de diferentes tipos de alimentos, assim como maus hábitos de higiene (Almeida \& Pena, 2011; França et al., 2013; Xavier, 2014).

No que diz respeito ao Complexo do Ver-o-Peso, a situação é semelhante. O Mercado de Peixe, por exemplo, apresenta condições higiênicas impróprias, relacionadas, sobretudo, a manipulação de alimentos, acúmulo de resíduos sólidos (Oliveira Souza et al., 2019) e armazenamento dos produtos (Alves et al., 2017; Rosário et al., 2020). Tal situação é frequentemente encontrada em outros setores do Complexo. Nascimento et al. (2020), ao realizarem análises parasitológicas em amostras de nove hortaliças comercializadas na Feira do Ver-o-Peso, obtiveram como resultado a contaminação de todas estas por parasitas. Este fato foi associado ao manuseio e manipulação do alimento durante a fase de plantio, transporte e comercialização.

Os perigos identificados e classificados como de risco 4 (sério) estão relacionados aos fatores mecânicos ou de acidentes que envolvem, entre outros fatores, a falta de atenção durante a manipulação e preparo de alimentos. Tal como o contato direto do trabalhador com objetos aquecidos e o manuseio incorreto de ferramentas/objetos perfurocortantes. Outro aspecto está relacionado as condições meteoceanográficas, associadas a fatores ambientais como maré alta, ventos e chuvas fortes. Além disso, também foi identificado a mesma classificação de risco para o agente ergonômico relacionado ao levantamento e transporte manual de peso, ligado a práticas de levantamento, transporte e descarga inadequada de materiais, além de condições ambientais inadequadas.

O perigo de queimadura pode ser observado em atividades associadas ao preparo de alimentos (Santos et al., 2014), podendo, inclusive, estar ligado ao nível de estresse no ambiente de trabalho (Haruyama et al., 2014). Em estudo sobre a incidência de acidentes ocupacionais não fatais em trabalhadores informais do comércio, foi mostrado que os principais acidentes apontados estavam relacionados ao corte com faca, lesão causada por parte estrutural da barraca e quedas (Rios et al., 2015). Entre os principais fatores associados estavam as variáveis sexo, idade, tipo de mercadoria comercializada, percepção de fatores de risco à saúde no processo de trabalho, esforço físico e demanda psicológica. Jahangiri et al. (2019), ao examinar a prevalência de lesões e doenças entre trabalhadores de restaurantes, observou resultados próximos, onde os acidentes estavam relacionados a cortes e lacerações decorrentes de acidentes com facas, queimaduras, quedas, escorregões e tropeções.

Quanto ao perigo relacionado as condições meteoceanográficas, o elevado índice pluviométrico de Belém (em torno de $3000 \mathrm{~mm} / \mathrm{ano}$ ), associado a outros fatores como urbanização acelerada, saneamento básico precário e a localização do Complexo, às margens da Baia do Guajará, tornam a área propícia a fatores ambientais de maré alta e de ventos e chuvas fortes, capazes de ocasionar inúmeros danos associados, sobretudo, ao alagamento (Tavares, 2008; Pontes et al., 2017; Moreira et al., 2019).

O risco ergonômico relacionado ao perigo de levantamento e transporte de peso é capaz de causar inúmeros problemas a saúde (Ferreira \& Nascimento, 2015). No transporte manual de cargas, o trabalhador precisar ser treinado a respeito das técnicas adequadas de manuseio de carga, não permitindo que o peso ponha sua saúde e segurança em risco. Nessa 
perspectiva, em estudo realizado por Assis Rocha et al. (2012), ao analisar o trabalhado dos carregadores de açaí no Complexo do Ver-o-Peso, foi observado uma relação direta entre o carregamento de cargas e os sintomas de dores osteomusculares, sobretudo nas regiões: dorsal inferior, dorsal superior e nos membros inferiores. Relatos de distúrbios osteomusculares também foram observados por feirantes do setor de hortifruti do Complexo (Brito et al., 2019). O que evidencia a necessidade das ações preventivas e de mitigação propostas neste estudo.

Os perigos de classificação 3 (moderado) englobam todas as ameaças identificadas como de risco físico, químico e a maior parte dos agentes ergonômicos e mecânicos ou de acidentes. No que tange aos riscos físicos, destacam-se o calor e o ruído, comuns em toda a área do Complexo. O ruído tem como origem o intenso fluxo de pessoas, a conversação entre feirantes e visitantes, o uso/funcionamento de equipamentos e o trânsito intenso nas vias próximas ao Complexo. Em algumas áreas específicas, como no Mercado de Carne, Mercado de Peixe e na zona de venda de maniva, onde ocorrem a utilização de equipamentos, como trituradores e serras fita, a percepção dos ruídos tona-se maior. Outros riscos físicos identificados no local estão diretamente relacionados a falta de uma infraestrutura adequada. A cobertura das barracas, por exemplo, encontra-se danificada em diversas áreas, o que permite a invasão da água da chuva e a proteção ineficaz de feirantes e clientes contra os raios solares, aumentando ainda mais a sensação térmica do local. Além disso, a falta de manutenção permite que haja infiltrações nas paredes e empoçamento de água da chuva.

Conforme a NR 15, o nível máximo de ruído para a exposição de oito horas diárias sem o uso de proteção é de $85 \mathrm{~dB}$, sendo vetado a exposição a níveis de ruído acima de $115 \mathrm{~dB}$ para indivíduos que não estejam adequadamente protegidos. Nesse sentido, não foi observada a utilização de EPIs por parte dos feirantes, o que traz preocupação quanto à saúde e bemestar destes trabalhadores. Problemas semelhantes, envolvendo níveis elevados de ruído em feiras livres, também foram observados por Silva et al. (2016) e Ruwer (2020). Onde a principal causa estava relacionada, sobretudo, à grande circulação de pessoas, principalmente nos finais de semana. Montelo et al. (2011), destacam que o calor é um sério problema enfrentado por feirantes, sobretudo os da área hortifrutigranjeira. Os autores ressaltam a importância de se considerar a natureza perecível dos produtos ofertados e a necessidade de medidas corretivas eficazes.

Os riscos químicos encontrados in loco estão relacionados principalmente a manipulação e preparo de alimentos. Incluindo a fumaça proveniente da queima do carvão (Montelo et al., 2011). Além disso, também foi observado a presença de produtos de higiene com potencial de contaminação, tal como água sanitária, álcool e desinfetantes. Nesse sentido, diversas substancias químicas, quando absorvidas em doses elevadas pelo organismo, seja pela via respiratória, digestiva, dérmica, parental ou ocular, são potenciais causadoras de diversas lesões no organismo, tal como queimaduras, encefalopatias, ulceras cutâneas e perturbações cutâneas (Sousa et al., 2005). Pereira (2015, p. 40) também destaca à inalação de poeira em feiras livres, que pode ocorrer “(...) a partir do manuseio de aves, das fezes solidificadas das mesmas e da areia no piso das gaiolas".

Outros aspectos relevantes, também classificados como de risco 3 estão associados aos perigos ergonômicos. Onde notou-se que muitos feirantes passam boa parte do tempo sentados ou em pé, com destaque para os vendedores de roupas, calçados, quebradores de castanha, artesãos, cozinheiros e açougueiros. O acômodo da posição possibilita disfunções ao corpo pela demanda de período. Lesões nos músculos extensores do corpo podem ocasionar fortes dores aos comerciantes. Na postura em pé, o sangue terá menos circulação no corpo, proporcionando varizes nas regiões das pernas e pés, além de compressões musculares (Werner et al., 2003). Além disso, também foi perceptível a quantidade de comerciantes que exerciam os mesmos movimentos repetidas vezes, tornando isto uma rotina frequente às funções do corpo. $\mathrm{O}$ que pode ocasionar o surgimento de Distúrbios Osteomusculares Relacionados ao Trabalho ou Lesões por Esforço Repetitivo. Estes têm características no uso exacerbado do sistema musculoesquelético com pouco período ao descanso, realizando novamente as mesmas funções. Há ocorrência de várias consequências como dores, parestesia, fadiga, contrações musculares, falta de ar e náuseas (Lima \& Nogueira, 2018). 
Os perigos mecânicos ou de acidentes classificados como de risco 3 estão associados a falta de atenção, desorganização do ambiente de trabalho e a ausência de manutenção envolvendo equipamentos e a infraestrutura local. De acordo com Montelo et al (2011), torna-se necessário a capacitação frequente dos feirantes visando a prevenção de acidentes, uma vez que o trabalhador pode atuar como agente preventivo. Garcia e Cremonesi (2006) atentam para a importância da criação e manutenção de programas prevencionistas como subsídios para a análise de riscos.

O perigo de classificação 2 (menor), apesar de enquadrado em categoria inferior aos outros perigos, também deverá ser observado e neutralizado a partir da “(...) implementação das medidas corretivas e/ou preventivas sugeridas” (Viana et al., 2014, p. 3297).

\section{Conclusão}

$\mathrm{Na}$ presente pesquisa, foi possível constatar os riscos mais comuns e capazes de ocasionar inúmeros danos à saúde, acidentes e doenças ocupacionais aos trabalhadores do Complexo do Ver-o-Peso. A origem dos riscos encontrados advém de distintos elementos do processo de trabalho como os materiais, equipamentos, conforto acústico e térmico, instalações e iluminação.

Observou-se que os feirantes estavam expostos aos fatores de riscos físicos, químicos, biológicos, ergonômicos e mecânicos ou de acidentes, sendo o biológico com o maior potencial de risco para os trabalhadores locais. Os riscos físicos, químicos e a maior parte dos agentes ergonômicos e mecânicos ou de acidentes apresentam potencial de risco moderado.

Em vista da análise dos resultados, revela-se a necessidade de investimentos do poder público, voltadas ao treinamento e capacitação dos profissionais envolvidos, sobretudo quanto ao cuidado e tratamento dos alimentos comercializados no Complexo. Além disso, observa-se a necessidade de melhorias na estrutura física, como reparos nas instalações elétricas e modernização das instalações e equipamentos utilizados, de modo a contribuir para a diminuição na ocorrência de potenciais perigos, assim como na utilização de EPIs.

Por fim, sugere-se que, em estudos futuros, sejam quantificados determinados aspectos ambientais, tal como as condições de conforto acústico, lumínico e de potencial de exposição ao calor ambiental.

\section{Referências}

Aguiar, L. A. (2011). Metodologias de Análise de Riscos - APP \& Hazop.

Almeida, M. D., Pena, P. G. L. (2011). Feira livre e risco de contaminação alimentar: estudo de abordagem etnográfica em Santo Amaro, Bahia. Revista Baiana de Saúde Pública, 35(1), 110-110.

Alves, E. M. P., Silva, A., Sousa, C. L., Figueiredo, H. M., \& Neves, E. A. (2017). Aspectos higiênicos-sanitários das instalações do mercado Ver-o-Peso e avaliação da temperatura dos peixes comercializados. Ciência \& Desenvolvimento-Revista Eletrônica da FAINOR, 10(2).

Almondes Teixeira, S., Santos Luz, N., De Oliveira, E. S., De Almondes, R. S., De Lucena, J. D., \& De Barros, H. B. (2015). Investigação dos riscos ambientais e ergonômicos em restaurantes privados de um município do Piauí-Brasil. RevInter, 8(1).

Amorim, E. D. (2010). Ferramentas de Análise de Risco. Apostila do curso de Engenharia Ambiental da Universidade Federal de Alagoas, CTEC, Alagoas.

Assis Rocha, J. B., Flores, E. R. M., Lima, L. C., \& De Jesus Rodrigues, L. (2012). Carregadores de açaí: análise ergonômica do trabalho de carregadores de açaí do Mercado Ver-o-Peso em Belém do Pará. Estudos e Pesquisas em Psicologia, 12(2), 431-445.

Azevedo, F. F., Queiroz, T. A. N. (2013). As Feiras Livres E Suas (Contra) Racionalidades: Periodização E Tendênciasa Partir De Natal-RN-Brasil. Geografía y CIENCIAS SOCIALES, Barcelona, 18(1009), 15.

Barros, S. S. (2013). Análise de Riscos. Curitiba: Instituto Federal do Paraná - Educação à Distância - e-Tec Brasil.

Brito, C. M. M., Nascimento, W. V. S., Araújo Lameira, S. M. (2019). As Doenças Ocupacionais Em Feirantes Do Ver-O-Peso. Colóquio Organizações, Desenvolvimento e Sustentabilidade - CODS, v. 10.

Carvalho, L. (2011). Ver-o-Peso. Belém: IPHAN. https://casadopatrimoniopa.files.wordpress.com/2013/12/guia_impressc3a3o.pdf

Carvalho, R. G. D., Oliveira, I. A. D., Maia, L. M., Maciel, R. H., \& Matos, T. R. (2016). Situações de trabalho e relatos de dor entre feirantes de confecções. Revista Psicologia Organizações e Trabalho, 16(3), 274-284. 
Castro, N. M., Dos Santos Soares, H. P., \& Arão, I. R. (2019). Análise Preliminar De Riscos Em Um Açougue Do Município De Rio Verde. Revista Interdisciplinar de Pós-graduação da UniAraguaia, 2(1), 99-110.

Dogramadzi, S., Giannaccini, M. E., Harper, C., Sobhani, M., Woodman, R., \& Choung, J. (2014). Environmental hazard analysis-a variant of preliminary hazard analysis for autonomous mobile robots. Journal of Intelligent \& Robotic Systems, 76(1), 73-117.

DPJ. (2015). Revitalização da feira do Ver-o-Peso: projeto básico. Belém.

Ferreira, N. F., Pereira, R. A. C. B., Do Santos Beguine, L., Fujimori, A. S. S., Luciano, D. M. B., Franco, E. F., ... \& Soares, V. M. (2020). Evaluation of the hygienic and sanitary conditions of food places commercialized at the free fairs of the city of Bauru/SP and the satisfaction of customers. Brazilian Journal of Health Review, 3(4), 11343-11364.

Ferreira, R. G. S., Nascimento, J. L. (2015). Lombalgia provocada pelo transporte manual de carga: uma reflexão coletiva sobre a saúde do trabalhador. Rev Saúde Desenv [on-line], 8(4), 207-21.

França, B. R., Bonnas, D. S., \& Silva, C. M. O. (2013). Qualidade higiênico sanitária de alfaces (Lactuca sativa) comercializadas em feiras livres na cidade de Uberlândia, MG, Brasil. Bioscience Journal, 30(3).

Haruyama, Y., Matsuzuki, H., Tomita, S., Muto, T., Haratani, T., Muto, S., \& Ito, A. (2014). Burn and cut injuries related to job stress among kitchen workers in Japan. Industrial health, 2013-0143.

Garcia, J. M. R., Cremonesi, K.C. P. (2006). Programas prevencionistas: subsídios para análise de riscos. Goiânia: AB.

Jahangiri, M., Eskandari, F., Karimi, N., Hasanipour, S., Shakerian, M., \& Zare, A. (2019). Self-reported, work-related injuries and illnesses among restaurant workers in Shiraz City, South of Iran. Annals of global health, 85(1).

Jesus Carvalho, J., Aguiar, M. G. G. (2017). Qualidade De Vida E Condições De Trabalho De Feirantes. Revista de Saúde Coletiva da UEFS, 7(3).

Lima, F; Nogueira, R. (2018). A efetividade do programa de ginástica laboral. Revista de Administração de Roraima - RARR, 7(2), $297-309$.

Martins, A. G., Ferreira, A. C. S. (2018). Caracterização das condições higiênico-sanitária das feiras livres da cidade de Macapá e Santana-AP. Revista Arquivos Científicos (IMMES), 1(1), 28-35.

Mascarenhas, G., Dolzani, M. C. (2008). Feira livre: territorialidade popular e cultura na metrópole contemporânea. Ateliê Geográfico, $2(2), 72-87$.

Minnaert, A. C. D. S. T., Freitas, M. D. C. S. (2010). Práticas de higiene em uma feira livre da cidade de Salvador (BA). Ciência \& Saúde Coletiva, 15, 16071614 .

Montelo, R. O., De Souza Martins, G. A., \& Teixeira, S. M. F. (2011). Avaliação das Condições de Higiene e Segurança do Trabalho: Estudo de Caso na Feira Livre do Agricultor em Palmas-Tocantins. Journal of Health Sciences, 13(4).

Moreira, F. S. A., Dias, G. F. M., Vitorino, M. I., Silva, J. C. C. (2019). Efeitos da precipitação e topografia para o risco de inundações na cidade de BelémPA. Revista Brasileira de Geografia Física, 12(7), 2716-2728.

Nascimento, L. T. A., Rodrigues, C. I. (2011). Sociabilidades no mercado de peixe do Ver-o-Peso: das práticas cotidianas à festa de Nossa Senhora de Nazaré. Revista Pós Ciências Sociais, 8(16).

Neves, C. R. F., Da Costa, V. C. (2019). Avaliação Preliminar de Risco (APR) em atividades ecoturísticas na trilha do Pico da Tijuca, Parque Nacional da Tijuca (RJ). Revista Brasileira De Ecoturismo (RBEcotur), 12(5).

NR 15. Norma Regulamentadora 15. Atividades E Operações Insalubres. https://sit.trabalho.gov.br

NR 17. Norma Regulamentadora 17. Ergonomia. https://sit.trabalho.gov.br

NR 9. Norma Regulamentadora 9. Programa De Prevenção De Riscos Ambientais. https://sit.trabalho.gov.br

NHO 06. Norma De Higiene Ocupacional: procedimento técnico: avaliação da exposição ocupacional ao calor. (2a ed.), Fundacentro, 2017.

Oliveira Souza, E. R., Da Silva, B. P., Do Canto, L. O., \& Pontes, A. N. (2019). Resíduos de peixe do Mercado de Ferro, Complexo do Ver-o-Peso, Belém, Pará. Revista Verde de Agroecologia e Desenvolvimento Sustentável, 14(4), 562-570.

Oliveira Souza, E. R., Pontes, A. N. (2020). Mercados públicos da Cidade de Belém do Estado do Pará, Brasil: Inventário dos pescados comercializados e condições higiênico-sanitárias. Research, Society and Development, 9(8), e647985971-e647985971.

Pereira, A. S., Shitsuka, D. M., Parreira, J. F., Shitsuka, R. (2018). Metodologia da pesquisa científica. Ed. UAB/NTE/UFSM.

Pereira, E. M. R. (2015). Riscos relacionados ao trabalho em feira livre: uma abordagem sobre a percepção de feirantes. Dissertação (Mestre em Saúde, Ambiente e Trabalho.) - Universidade Federal da Bahia, Faculdade de Medicina da Bahia, Programa de Pós-Graduação em Saúde, Ambiente e Trabalho.

Pontes, M. L. C., De Lima, A. M. M., Júnior, J. D. A. S., \& De Azevedo Sadeck, C. C. (2017). Dinâmica das áreas de várzea do município de Belém/PA e a influência da precipitação pluviométrica na formação de pontos alagamentos. Caderno de Geografia, 27(49), $285-303$.

Pombo Geertsma, I. (2019). Medicinal botany of the Historia Naturalis Brasiliae (1648) compared to the market Ver-o-Peso in Belém, Pará, Brazil, with a focus on AfroBrazilian and women's health plants. MSc Thesis. Univ.Amsterdam, The Netherlands, pp. 36. 
Rios, M. A., Nery, A. A., Rios, P. A. A., Casotti, C. A., \& Cardoso, J. P. (2015). Fatores associados a acidentes de trabalho envolvendo trabalhadores informais do comércio. Cadernos de Saúde Pública, 31, 1199-1212.

Rodríguez, M. A., Geertsma, I. P., Françozo, M., \& Van Andel, T. (2020). Marcgrave and Piso's plants for sale: The presence of plant species and names from the Historia Naturalis Brasiliae (1648) in contemporary Brazilian markets. Journal of Ethnopharmacology, 112911.

Rosário, J. V. S., De Alcântara, B. L., Santa Rosa, R. M. S., Da Silva, P. A., Da Silva, F. E. R., \& Bichara, C. M. G. (2020). Adequações higiênico-sanitárias e físico-estruturais dos boxes de comercialização de peixes no mercado do Ver-O-Peso, em Belém/PA. Brazilian Journal of Development, 6(8), $59153-59167$.

Ruwer, L. M. E. (2020). Meio ambiente e seus desafios: Estudos Contemporâneos - Volume 1.: Editora Poisson, $1,176$.

Saliba, T. M. (2019). Manual prático de higiene ocupacional e PPRA: avaliação e controle dos riscos ambientais. (10a ed.), LTr.

Santos, E. A., Braga D. D., Fuculo Junior, P. R. B., Oliveira, T. D., Bazzan, J. S., Echevarría-Guanilo, M. E. (2014). Ocupações com maior risco para acidente com queimaduras. Revista Brasileira de Queimaduras, 13(4), 260-264.

Santos, M. C., Sepêda Filho, M. G. (2016). Entre horizontalidades e verticalidades: o Ver-o-Peso no contexto do processo de "revitalização" urbana. In: Encontro Nacional De Geógrafos. 18. São Luís. Cidade e Urbano, p. 1-13.

SECON (2019). REFORMA - Projeto de revitalização do Ver-o-Peso é apresentado para feirantes. http://www.belem.pa.gov.br/secon/site/2019/05/14/reforma-projeto-de-revitalizacao-do-ver-o-peso-e-apresentado-para-feirantes/

Silva, J. R. A. E. (2018). Gestão De Negócios-Planejamento E Organização Para Indústria. Saraiva Educação AS.

Silva, R. B., Nääs, I. D. A., Silveira, N., \& De Moura, D. J. (2006). Insalubridade do trabalhador na produção animal: uma questão de educação e informação. Segurança e Trabalho, Brasil.

Silva, T. L. C. V. (2011). Etnografando mercados: trabalho, sociabilidade e lazer no Ver-o-Peso. Somanlu: Revista de Estudos Amazônicos, 11(1), 27-44.

Silva A. F., Calil, R. M., Calil, E. M. B. (2015). A problemática ambiental em relação aos resíduos sólidos, ruídos e odores em feiras livres na cidade de Osasco. Atas de Saúde Ambiental - ASA (São Paulo, Online), 3(2), 30-37.

Sousa, E., Alves, R. J. M., Silva, J. M., Miranda, N. (2017). Prospecção socioeconômica em feiras livres: o caso do Complexo do Ver-o-Peso, Belém, Pará, Brasil. Revista Espacios, 38(36).

Sousa, G. G., Medeiros Jerônimo, C. E. (2014). Análise Preliminar de Riscos Ambientais para Atividades Relacionadas a Perfuração de um Poço de Petroleo Terrestre. Revista Monografias Ambientais, 13(3), 3265-3277.

Souza, E. R. O., Da Silva, B. P., Do Canto, L. O., \& Pontes, A. N. (2019). Resíduos de peixe do Mercado de Ferro, Complexo do Ver-o-Peso, Belém, Pará. Revista Verde de Agroecologia e Desenvolvimento Sustentável, 14(4), 562-570.

Sousa, J., Silva, C., Pacheco, E., Moura, M., Araújo, M., \& Fabela, S. (2005). Acidentes de Trabalho e Doenças Profissionais em Portugal: Riscos Profissionais: Factores e Desafios. Vila-Nova de Gaia: Centro de Reabilitação Profissional de Gaia.

Taketa, B. V., Neto, G. G., Trindade Júnior, S. C. C. (2018). Projeto "novo" Ver-o-Peso: cidadania e dilemas do planejamento e da participação social em Belém (PA). PAPERS DO NAEA (UFPA), 396, 03-18.

Tavares, J. P. N. (2008). Enchentes repentinas na cidade de Belém-PA: condições climáticas associadas e impactos sociais no ano de 1987. Caminhos de Geografia, $9(28)$.

Teixeira, J. M. J.; Coutinho, E. C. (2010). Feira Livre do Entroncamento em Belém-PA: da precarização à promoção da qualidade ambiental. Educação Ambiental em Ação, 33, 03.

Vedana, V. (2013). Fazer a feira e ser feirante: a construção cotidiana do trabalho em mercados de rua no contexto urbano. Horizontes Antropológicos, 19(39), 41-68.

Viana, M. G. P., Alves, C. S., \& De Medeiros Jerônimo, C. E. (2014). Análise Preliminar De Riscos Ambientais Na Atividade De Acabamento E Revestimento Externo De Um Edifício. Revista Monografias Ambientais, 13(3), 3289-3298.

Wachowicz, M. C. (2012). Segurança, saúde e ergonomia. (2a ed.) Rev. atual. e ampl. Curitiba: Ibpex.

Werner, L.; Linden, J. C. S. V. D; Ribeiro, J. L. D. (2003). Análise da percepção sobre assentos de trabalho utilizando técnicas estatísticas multivariadas. Revista Produção, 13(3), 34-49.

Xavier, D. M. (2014). Caracterização higiênico-sanitária de restaurantes comerciais do município de Botucatu-São Paulo. Dissertação (Mestre em Medicina veterinária) - Universidade Estadual Paulista, Faculdade de Medicina Veterinária e Zootecnia. 